\title{
Bacterial translocation and microgap formation at a novel conical indexed implant abutment system for single crowns
}

\author{
Peter Gehrke ${ }^{1,2}$ - Simon Burg ${ }^{3} \cdot$ Ulrike Peters ${ }^{4} \cdot$ Thomas Beikler $^{4} \cdot$ Carsten Fischer $^{5}$ (C) Frank Rupp $^{6}$. \\ Ernst Schweizer ${ }^{6} \cdot$ Paul Weigl $^{1} \cdot$ Robert Sader $^{7} \cdot$ Ralf Smeets $^{3,8} \cdot$ Sogand Schäfer $^{3}$
}

Received: 14 June 2021 / Accepted: 27 July 2021 / Published online: 16 August 2021

(c) The Author(s) 2021

\begin{abstract}
Objectives A conometric concept was recently introduced in which conical implant abutments hold the matching crown copings by friction alone, eliminating the need for cement or screws. The aim of this in vitro study was to assess the presence of microgap formation and bacterial leakage at the Acuris conometric restorative interface of three different implant abutment systems. Material and methods A total of 75 Acuris samples of three implant-abutment systems (Ankylos, Astra Tech EV, Xive) were subjected to microbiological ( $n=60)$ and scanning electron microscopic (SEM) investigation $(n=15)$. Bacterial migration into and out of the conical coupling system were analyzed in an anaerobic workstation for 48, 96, 144, and $192 \mathrm{~h}$. Bacterial DNA quantification using qrt-PCR was performed at each time point. The precision of the conometric coupling and internal fit of cemented CAD/CAM crowns on corresponding Acuris TiN copings were determined by means of SEM.

Results qrt-PCR results failed to demonstrate microbial leakage from or into the Acuris system. SEM analysis revealed minute punctate microgaps at the apical aspect of the conometric junction (2.04 to $2.64 \mu \mathrm{m}$ ), while mean cement gaps of 12 to $145 \mu \mathrm{m}$ were observed at the crown-coping interface.

Conclusions The prosthetic morse taper connection of all systems examined does not allow bacterial passage. Marginal integrity and internal luting gap between the ceramic crown and the coping remained within the clinically acceptable limits. Clinical relevance Conometrically seated single crowns provide sufficient sealing efficiency, relocating potential misfits from the crown-abutment interface to the crown-coping interface.
\end{abstract}

Keywords Acuris · Conometric connection $\cdot$ Bacterial leakage $\cdot$ Microgap $\cdot$ Cement gap $\cdot$ Marginal integrity $\cdot$ CAD/CAM crown

\section{Introduction}

Anchorage of the prosthetic connection for implantsupported fixed dental prostheses (FDPs) is commonly achieved by means of luting cement or screws. To ensure firm retention between multiple implants and the respective superstructure, the use of a conometric concept has been proposed alternatively $[1,2]$. In this approach, conical abutments retain matching crown copings solely by surface friction, thus eliminating the need for either cement or screws. Recently, a novel conical indexed abutment (Acuris, Dentsply Sirona Implants, Mölndal, Sweden) with anti-rotation features has been introduced

Peter Gehrke

dr-gehrke@prof-dhom.de; gehrke@med.uni-frankfurt.de

Extended author information available on the last page of the article to avoid the undesirable impact of rotational forces in single implant restorations [3, 4]. A modification of this restorative concept from previously published conometric approaches involves extraoral adhesive luting between a titanium nitride-coated (TiN) stock coping (Acuris Cap, Dentsply Sirona Implants, Mölndal, Sweden) and an all-ceramic crown in the dental laboratory, shifting the potential misfits from the crown-abutment interface to the crown-coping interface (Fig. 1). The final crown-coping complex is fixed intraorally to the anti-rotation connection of the conical abutment with an axially directed load of a calibrated striker (Acuris Abutment, Conometric Fixation Tool, both Dentsply Sirona Implants, Mölndal, Sweden). This ensures a correct alignment and secure coupling of the crown. The conometric joint is therefore a fixed retention, with the possibility of maintenance-related disengagement by the dentist. 


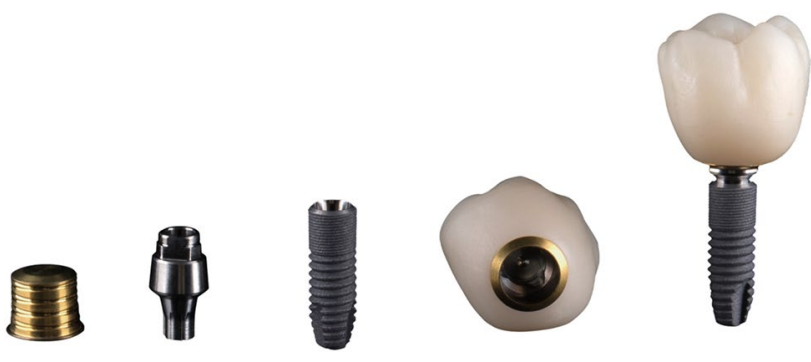

Fig. 1 Components of Acuris conical indexed abutment-system illustrated by the example of Astra Tech EV (from left to right): titaniumnitride (TiN) Acuris cap, conical Acuris abutment with anti-rotation connection, implant, extraorally luted all-ceramic crown on TiN cap, conometrically fixed crown-coping complex on assembled abutment

Unlike traditional fixation methods for the retention of implant-supported reconstructions achieved by either cement- or screw-retaining techniques, the morse taper coupling connection exhibits an inherently superior accuracy, as the FDP abutment connection is achieved by prefabricated, intraorally passivated components. In addition, beneficial clinical outcomes were observed with regard to the prevention of undesirable technical and/or biological prosthetic complications such as screw loosening, fracture, ceramic chipping, debonding of the restoration, undetected cement remnants and subsequent peri-implant tissue inflammation, and/or crestal bone loss [5, 6]. Occlusal openings and related interferences in the veneering surface, as required for a screw-retained approach, are not present.

Despite the promising clinical results for conometric morse taper connections used to retain implant-supported single crowns (SCs) and FPDs, there are limited data on the accuracy of fit at the level of restoration and the potential for bacterial leakage at the conical coupling [7]. A misalignment and resulting microgap between the conometric units could serve as a bacterial reservoir that facilitates plaque formation. This, in turn, may promote inflammation of the peri-implant tissues and crestal bone resorption. Furthermore, the interaction between metal surfaces and the oral environment may lead to the release of implant degradation products into the peri-implant sulcus, which exposes the microbiota to increased environmental stress and subsequently change immune responses to bacteria $[8,9]$. A recent pilot study on the microbiological sealing of the novel Acuris junction revealed no bacterial translocation at the conometric interface [10]. However, since this investigation only examined a relatively small number of specimens for a single implant system, verification of these results in a larger group of specimens for different implant abutment configurations is required. The marginal integrity and internal fit of the extraorally luted ceramic crowns on the matching copings is yet to be verified.
The aim of the present in vitro trial was therefore to evaluate the bacterial leak proofing along the conometric junction of 3 different implant-abutment systems for single crown restorations. A secondary objective of the study was to assess the conometric fit as well as the marginal adaption of computer-assisted design and computer-assisted (CAD/CAM) fabricated all-ceramic crowns on the Acuris TiN copings using scanning electron microscopy (SEM). The hypothesis tested was that the cone-in-cone coupling exhibits no detectable microgap and does not allow bacterial translocation, irrespective of the implant-abutment system. Furthermore, it was hypothesized that no difference would be observed between the 3 test groups in terms of internal fit and marginal integrity of the crown-coping interface.

\section{Materials and methods}

\section{General study setup}

A dual study approach was designed to evaluate bacterial leakage along the Acuris morse taper junction and to determine its conometric fit as well as the internal and marginal integrity between the Acuris TiN coping and all-ceramic crown. The principal scheme of the test setup is shown in Fig. 2. A total of 75 conometric samples of three different implant-abutment systems (Ankylos C/X A11 implant, D 3,5/ L11; Astra Tech EV implant, D 3.6/ L 11, and Xive S plus implant; D 3.8/ L 11, all Dentsply Sirona Implants, Mölndal, Sweden) were subjected to microbiological $(n=60)$ and microscopic investigation $(n=15)$. The examined specimens had distinct system-inherent morse taper (Ankylos C/X and Astra Tech EV) or internal hex (Xive S plus) implant-abutment junctions (IAJ) (Fig. 3).

\section{Analysis of bacterial translocation}

To examine bacterial migration into and out of the restorative conometric coupling system, separate microbiological tests were conducted. First, ten conometric abutments (Acuris, A0, GH 1 to $1.5 \mathrm{~mm}$, Dentsply Sirona implants, Mölndal, Sweden) of each system were connected to the corresponding screw implants (subtotal $n=30$ ). This involved the unpacking of the sterile implants and connecting the Acuris abutments to the implants using a new titanium abutment screw and tightening it to the manufacturer's recommended insertion torque using a pre-calibrated manual torque wrench for each system. Titanium nitride-coated (TiN) stock copings (Acuris Cap, Dentsply Sirona implants, Mölndal, Sweden) were attached manually to the anti-rotation portion of the abutments. The friction fit was obtained by exerting an axially directed load using a dedicated fixation tool with a calibrated striker (Conometric fixation tool; 


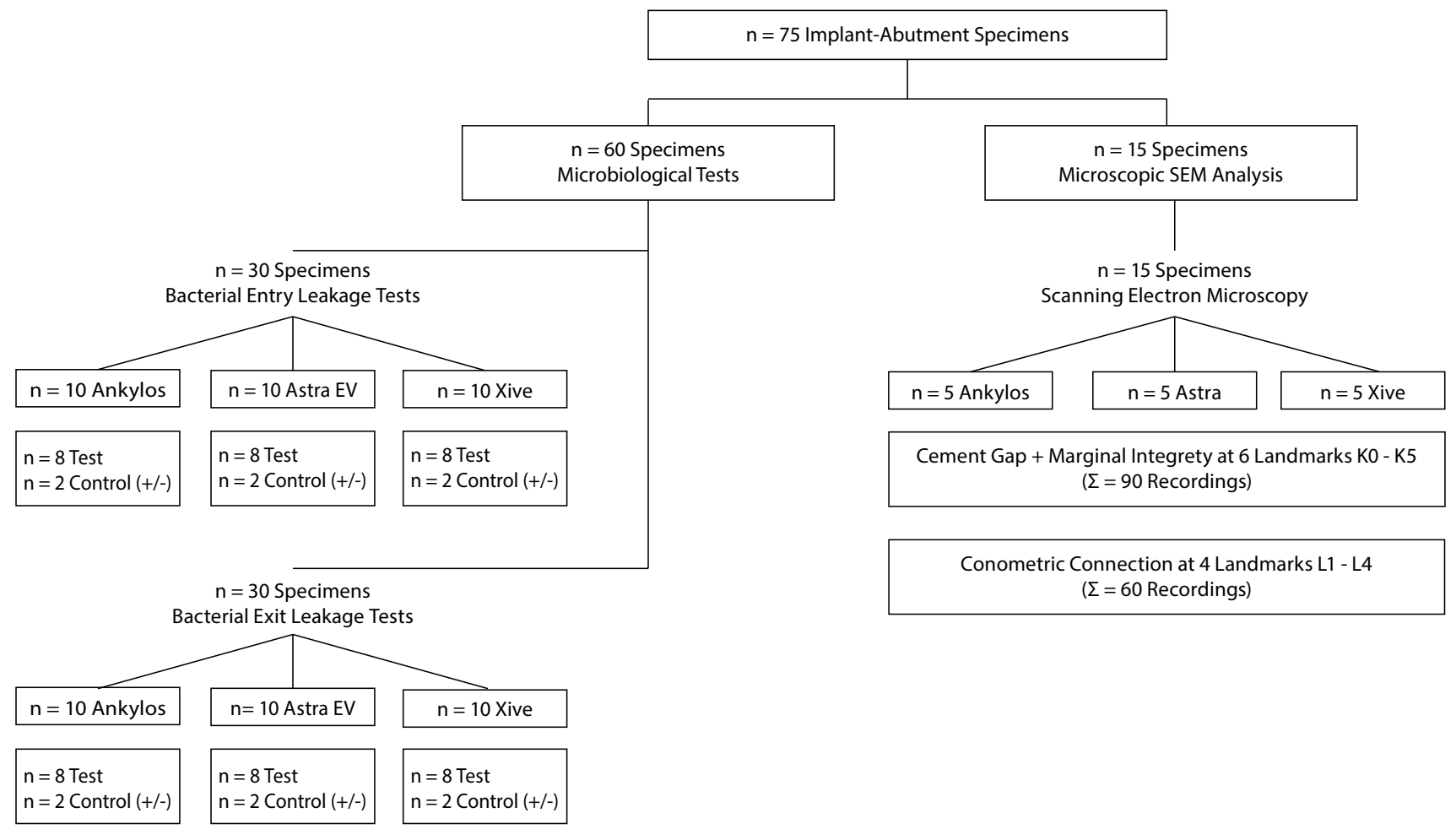

Fig. 2 Study design of qrt-PCR microbiological analyses and microscopic examination by means of SEM
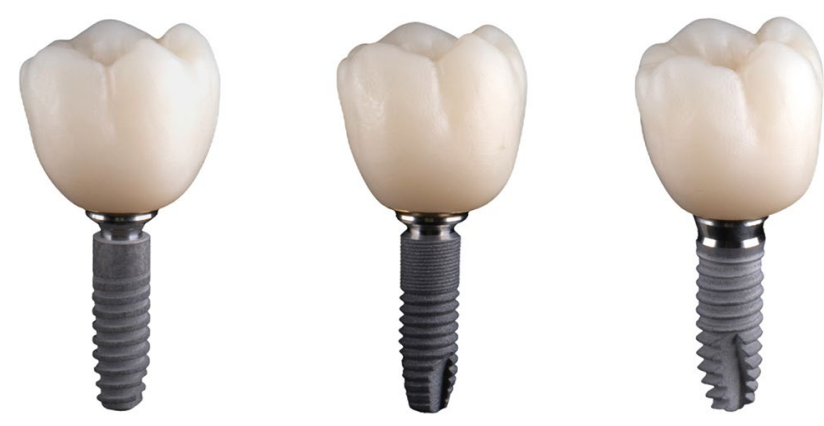

Fig. 3 Assembled specimens of the tested implant-abutment systems (from left to right): Ankylos C/X, Astra Tech EV, Xive S plus

Dentsply Sirona Implants, Mölndal, Sweden). Similar to a clinical setting, final fixation of the TiN copings was verified visually and by manual, non-calibrated pull-off tests. All specimens were finally autoclaved (Autoclave Systec V-40, Systec GmBH, Linden, Germany) and transferred to a Whitley A35 workstation (Whitley A35 Workstation Don Whitley Scientific, Bingley, UK) under anaerobic conditions at $37{ }^{\circ} \mathrm{C}$. For screening of bidirectional bacterial translocation, a mixed bacterial culture suspension consisting of anaerobic early colonizing Streptococcus mutans (DSM 20,523, German Collection of Microorganisms and Cell Cultures GmbH, Leibnitz, Germany), moderate colonizing Actinomyces naeslundii (DSM 17,233, German Collection of Microorganisms and Cell Cultures GmbH, Leibnitz, Germany), Fusobacterium nucleatum (DSM 15,643, German Collection of Microorganisms and Cell Cultures GmbH, Leibnitz, Germany), and late colonizing Porphyromonas gingivalis (DSM 20,709, German Collection of Microorganisms and Cell Cultures GmbH, Leibnitz, Germany) species was prepared. The bacteria varied by size with a size ranging from 0.5 to $1-2 \mu \mathrm{m}$ [11]. The optical density (OD) of the mixed culture was 0.1 .

To assess bacterial outgrowth, the occlusal openings of ten Acuris abutments in each of the three different systems were filled with $4 \mu \mathrm{l}$ of a mixed bacterial culture of anaerobes. The matching TiN caps were seated on the abutments and fixed as previously described. All assembled specimens were then disinfected with $70 \%$ aqueous ethanol (EtOH) and transferred to sterile $1.5 \mathrm{ml}$ Eppendorf tubes containing $1 \mathrm{ml}$ bacterial culture medium (CDC) to provide an optimal environment for bacterial colonization. While $4 \mu \mathrm{l}$ of mixed bacterial culture was filled directly into an Eppendorf tube as a positive control, $4 \mu$ l of pure culture medium (CDC) in one of the Acuris abutments served as a negative control. Incubation was maintained at $37{ }^{\circ} \mathrm{C}$ for $48,96,144$, and $192 \mathrm{~h}$. At each specified time interval, a sample of $50 \mu \mathrm{l}$ was taken from each Eppendorf tube for the analysis of total bacterial count. Each sample underwent DNA preparation (innuPREP DNA Isolation Kit, Analytik Jena AG, Jena, Germany). The respective DNA was quantified by qrt-PCR (quantitative 
real-time polymerase chain reaction, CFX96 Touch RealTime PCR Detection System, Bio-Rad Laboratories, Berkeley, California, USA) employing a universal eubacterial 16S rRNA primer (HDA1 GACTCCTACGGAGGCAGCAGT, E1115R AGGGTTGCGCTCGTTGCGG). Universal primer results were specified with appropriate primers for each bacterial strain as listed in Table 1 [10, 12-14].

To cross-check the findings concerning bacterial translocation out of the conometric components, samples were also tested for bacterial leakage into the conometric system. An additional ten Acuris abutments (subtotal $n=30$ ) of the respective systems (Ankylos C/X, Astra Tech EV, Xive S plus) were occlusally filled with $4 \mu \mathrm{l}$ of culture medium to ensure an optimal environment for bacterial colonization and connected to the Acuris TiN copings. The specimens were transferred to a reaction tube containing $30 \mathrm{ml}$ bacterial mixed culture solution. As a positive control, $4 \mu \mathrm{l}$ of bacterial mixed culture was filled directly into an Eppendorf tube. Four $\mu$ of culture medium (CDC) served as a negative control and replaced the bacterial mixed culture. Over a period of 7 days, a sample of $20 \mathrm{ml}$ of mixed culture solution was taken from the original reaction tube at $48,96,144$, and $192 \mathrm{~h}$, respectively, and replaced with fresh bacterial culture medium. Simultaneously, at each point of time, two implants were removed from the reaction tube, washed with phosphate buffered saline (PBS), and disinfected with $70 \%$ aqueous ethanol (EtOH), followed by removal of the TiN caps from the abutments. The contained solution was processed with a deoxyribonucleic acid (DNA) Isolation Kit (innuPREP DNA Isolation Kit, Analytik Jena AG, Jena, Germany). In concordance to outgrowth testing, the DNA was quantified with qrt-PCR using universal and specific primers for the examined bacterial strains [10, 12-14] (Table 1).

\section{SEM analysis of conometric connection and luting interface of coping and crown}

\section{Specimen fabrication}

In addition to bacterial leak testing, a total of 15 Acuris specimens for single crown restorations of the three different systems were subjected to scanning electron microscopy, five per system (Ankylos C/X, Astra Tech EV, Xive S plus). Despite different IAJ, the restorative abutment configuration and prosthetic diameter (D $4.5 \mathrm{~mm}$ ) were identical for all abutments. Thus, the same Acuris TiN copings could be used for all three implant systems. The master cast of a clinical case where the right mandibular first molar had been replaced by a single implant restoration served as origin of the virtual crown design (DentalCAD, Exocad GmbH, Darmstadt, Germany). A temporary implantsupported single crown had been used to precondition the emergence profile of the peri-implant mucosa. Due to the same restorative abutment configuration of all investigated systems, 15 identical monolithic CAD/CAM zirconia crowns were fabricated (Katana, Super Translucent Multi Layered, Kuraray Noritake Dental, Tokyo, Japan). A list of materials and manufacturers is shown in Table 2. Strict adherence to the manufacturer's recommendations was ensured for the bonding process of the all-ceramic crowns. The inner bonding surface of each crown was conditioned with a ceramic primer (Clearfil Ceramic Primer Plus, Kuraray Noritake Dental, Tokyo, Japan) for $5 \mathrm{~s}$ prior to bonding the crowns to the TiN copings with a Bis-GMA/TEGDMA-based cement (Panavia V5, Kuraray Noritake Dental, Tokyo, Japan). The excess of the resin composite cement was removed after the setting process was initiated by a 3-s light polymerization. To prevent an oxygen inhibition layer, the margins were covered with inhibitor gel (Panavia F 2.0 Oxyguard II, Kuraray Noritake Dental) before the curing process was completed by $15 \mathrm{~s}$ of light polymerization. Finally, the adhesive joint of each crown-cap unit was carefully polished with silicone polishers. After fabrication of the extraorally cemented crown-coping complexes, the Acuris abutments were connected to the implants as previously described and screwed in place with a dedicated torque wrench. The crown-coping units were then mounted on the anti-rotational part of the abutments and friction-fixed with the calibrated striker tool.

\section{SEM assessment}

All samples were processed for scanning electron microscopy (SEM) analysis of polished micrographs. The

Table 1 Specific primer sequences for qrt-PCR and references of their applicability [10]

\begin{tabular}{llll}
\hline Organism & Primer & Primer sequence & Reference of primer applicability \\
\hline Porphyromonas gingivalis & CA-PG-F/R & AGGCAGCTTGCCATACTGCG & Carrouel F. et al., 2016 [12] \\
Streptoccocus mutans & MKD-FV/RV & ACTGTTAGCAACTACCGATGT & Hoshino T. et al., 2004 [13] \\
Actinomyces species & ACT-174-F & GGCACCACAACATTGGGAAGCTCAG GGAATGGCCGCT & Bizhang M. et al., 2011 [14] \\
Fusobacterium nucleatum & ACT-281-R & AAGTCAACAGG & Carrouel F. et al., 2016 [12] \\
& CA-FN-F/R & GGTCTCTGGGCCGTTACTGA & \\
& & GRCCCCCCACACCTAGTG & \\
& & AGAGTTTGATCCTGGCTCAG & \\
& & GTCATCGTGCACACAGAATTGCTG
\end{tabular}


Table 2 List of materials, compositions, manufacturers, respective reference no. and quantity used

\begin{tabular}{|c|c|c|c|c|}
\hline Material & Composition & Manufacturer & Ref. No & Quantity \\
\hline Ankylos C/X A11 Implant (D 3,5/ L11) & Titanium grade 2 & Dentsply Sirona & 31010410 & 5 \\
\hline Astra Tech EV Implant (D 3.6/ L 11) & Titanium grade 2 & Dentsply Sirona & 25,224 & 5 \\
\hline Xive S plus Implant (D 3.8/ L 11) & Titanium grade 2 & Dentsply Sirona & 262442 & 5 \\
\hline $\begin{array}{l}\text { Ankylos Conometric Abutment C/ } 1.5 / 0^{\circ} / \\
\varnothing 4.5 / \mathrm{I}\end{array}$ & Titanium grade 2 & Dentsply Sirona & 31023450 & 5 \\
\hline $\begin{array}{l}\text { Astra Tech EV Conometric Abutment EV/ } \\
\varnothing 3.6 / 1.0 / 0^{\circ} / \varnothing 4.5 / \mathrm{I}\end{array}$ & Titanium grade 2 & Dentsply Sirona & 26,121 & 5 \\
\hline $\begin{array}{l}\text { Xive S plus Conometric Abutment/ } \\
\emptyset 3.8 / 1.0 / 0^{\circ} / \varnothing 4.5 / \mathrm{I}\end{array}$ & Titanium grade 2 & Dentsply Sirona & $32,264,101$ & 5 \\
\hline $\begin{array}{l}\text { Ankylos C/X, Astra Tech EV, XiVE S } \\
\text { plus Conometric Final Cap, } \varnothing 4.5\end{array}$ & Titanium Nitride & Dentsply Sirona & $31,072,303$ & 15 \\
\hline $\begin{array}{c}\text { Ankylos C/X, Astra Tech EV, XiVE S } \\
\text { plus Conometric Lab Analogs } \emptyset 4.5\end{array}$ & Surgical stainless steal & Dentsply Sirona & 31072020 & 15 \\
\hline $\begin{array}{l}\text { Ankylos C/X, Astra Tech EV, XiVE S } \\
\text { plus Conometric Lab Cap Ø4.5 }\end{array}$ & Ti6AL4V-ELI & Dentsply Sirona & 31072123 & 15 \\
\hline Fixation Tool Acuris & Surgical stainless steal & Dentsply Sirona & 31072,911 & 1 \\
\hline Katana CAD/CAM Zirconia Crown & $\begin{array}{l}\mathrm{ZrO} 2+\mathrm{Y} 2 \mathrm{O} 3:>98,0(\mathrm{wt} \%) ; \text { pig- } \\
\text { ments }<=2,0(\mathrm{wt} \%) \\
\text { Super Translucent Multi Layered (STML) }\end{array}$ & Kuraray Noritake Dental & A3 125-3182EU & 15 \\
\hline Panavia V5 & $\begin{array}{l}\text { Monomer matrix: hydrophobic aromatic } \\
\text { dimethacrylate, hydrophilic aliphatic } \\
\text { dimethacrylate, Bis-GMA, TEGDMA; } \\
\text { inorganic fillers: silanated barium glass, } \\
\text { silanated fluoroaluminosilicate glass, } \\
\text { colloidal silica, silanated aluminum } \\
\text { oxide (particle size between } 0.01 \mu \mathrm{m} \\
\text { and } 12 \mu \mathrm{m} \text {, total volume content of inor- } \\
\text { ganic fillers approximately } 38 \text { vol\%); } \\
\text { initiators; accelerators; camphorquinone; } \\
\text { pigments }\end{array}$ & $\begin{array}{l}\text { Kuraray Noritake } \\
\text { Dental }\end{array}$ & $350008 / 680,008$ & $\begin{array}{l}\text { as } \\
\text { manufact } \\
\text { recomm }\end{array}$ \\
\hline Monobond Plus & $\begin{array}{l}\text { Ethanol, silane, methacrylate phosphoric } \\
\text { ester }\end{array}$ & Ivoclar Vivadent & X28859 & as needed \\
\hline Liquid Strip & Glycerin gel & Ivoclar Vivadent & X09458 & as needed \\
\hline Clearfil Ceramic Primer Plus & $\begin{array}{l}\text { Ethanol, 3-methacryloxypropyl trimeth- } \\
\text { oxy silane, } 10 \text {-methacryloyloxydecyl } \\
\text { dihydrogen phosphate }\end{array}$ & Kuraray Noritake Dental & 580035 & as needed \\
\hline Panavia F 2.0 Oxyguard II & $\begin{array}{l}\text { Glycerin, polyethylene glycol, katalysa- } \\
\text { tors, initiators, pigments }\end{array}$ & Kuraray Noritake Dental & 4R0003/ 6J0064 & as needed \\
\hline
\end{tabular}

specimens were embedded in a polyurethane-based model resin (Sherapolan 2:1, Shera Werkstofftechnologie) using UNICLIP specimen holders (Wirtz/Buehler) in a standardized process. Horizontal alignment and cutting to the required specimen sizes were performed automatically with an Accutom-50 precision grinding and cutting machine (Struers). After adjustment to the required parameters (accuracy, $\pm 5 \mu \mathrm{m}$, cut-off wheel width, $0.6 \mathrm{~mm}$ ), polished thin sections were prepared under water cooling and continuous examination of macro- and microscopic integrity (10 $\times$ magnification, photomacroscope, Wild). Subsequent to final inspection, samples were sputtered with $\mathrm{Au}-\mathrm{Pd}$ for SEM evaluation. Microgaps along the conometric connection and between the luting interface of the TiN coping and all-ceramic crown were measured for the 15 specimens by means of SEM (LEO 1430, Zeiss). In total, 150 SEM measurements, including 90 readings of the conical coupling and 60 recordings of the micro-cement-gap of the restoration, were taken. Distance measurements were evaluated by the same examiner (E.S.) and were made once for each predefined distance. Conical and marginal discrepancies were evaluated at $200 \times$ and $1000 \times$ magnification.

\section{SEM readings of conometric connection}

Potential microgaps between the TiN coping and titanium Acuris abutment were determined at four prespecified landmarks (L1 to L4) according to distinctive construction 
characteristics of the conometric connection (Fig. 4). A gap has been defined as the perpendicular distance from the surface of the axial wall of the abutment to the internal surface of the TiN coping. In the clinical situation, landmarks L1 and L4 are located directly within the periimplant sulcus with potential contact to the surrounding tissues of the oral cavity and were thus grouped as "external gaps." The remaining landmarks L2 and L3 comprised the mid vertical taper of the Acuris abutment and were consequently recorded as "internal gaps" for SEM analysis. Whereas the external microgaps determine the longterm performance in terms of bacterial leakage entrance, the internal gaps represent the extension of the morse taper junction and are additionally responsible for the mechanical and dimensional properties of the conometric coupling.

\section{SEM readings of crown-coping unit}

The size of the luting gap and the marginal integrity of the CAD/CAM ceramic crowns on the extraorally cemented Acuris TiN copings were evaluated in the same way at 6 defined reference points (K0 to K5) according to the respective design properties of the prefabricated copings (Fig. 4). While the landmarks $\mathrm{K} 0$ and $\mathrm{K} 5$ determined the discrepancy of the crown margin and the coping after cementation, the landmarks K1 to K4 represented the vertical and horizontal luting gaps inside the crown.

\section{Statistical analysis}

Statistical analysis was conducted using SAS 7.4 (SAS Institute Inc., Cary, North Carolina, USA) and BiAS 11.10 (Epsilon Publishing, Frankfurt, Germany). Mean bacterial counts from the qrt-PCR measurement were compared with an exponentiallinear model that included implant type and experimental time as fixed effects. The graphical representation is based on the marginal means estimated from the statistical model. Since the data of the SEM measurements were not normally distributed, Wilcoxon-Mann-Whitney tests were performed for pairwise comparison of restorations. Kruskal-Wallis $(\mathrm{H})$ and Chi-square tests $\left(\mathrm{Chi}^{2}\right)$ were used for the comparison of two or more independent groups. The level of significance was set at 5\% $(p<0.05)$ for all applied statistical tests.

\section{Results}

\section{Bacterial outgrowth}

The qrt-PCR results for all Acuris test samples revealed values approaching the negative control for bacterial leakage out of the conometric system. Statistical analysis demonstrated a significant difference for qrt-PCR readings of positive control and all test specimens $(p<0.0001)$ (Table 3, Fig. 5), whereas no difference was found between negative control and test specimens. Comparison of
Fig. 4 SEM of conometric connection (example: Ankylos C/X specimen) with landmarks L1 to L4. Luting gap and marginal integrity of ceramic crown on TiN coping are displayed at 6 defined reference sites $\mathrm{K} 0$ to $\mathrm{K} 5$. Points $\mathrm{K} 0$ and $\mathrm{K} 5$ represent the discrepancy between crown margin and coping after cementation. Landmarks K1 to $\mathrm{K} 4$ represent the vertical and horizontal luting gaps inside the crown

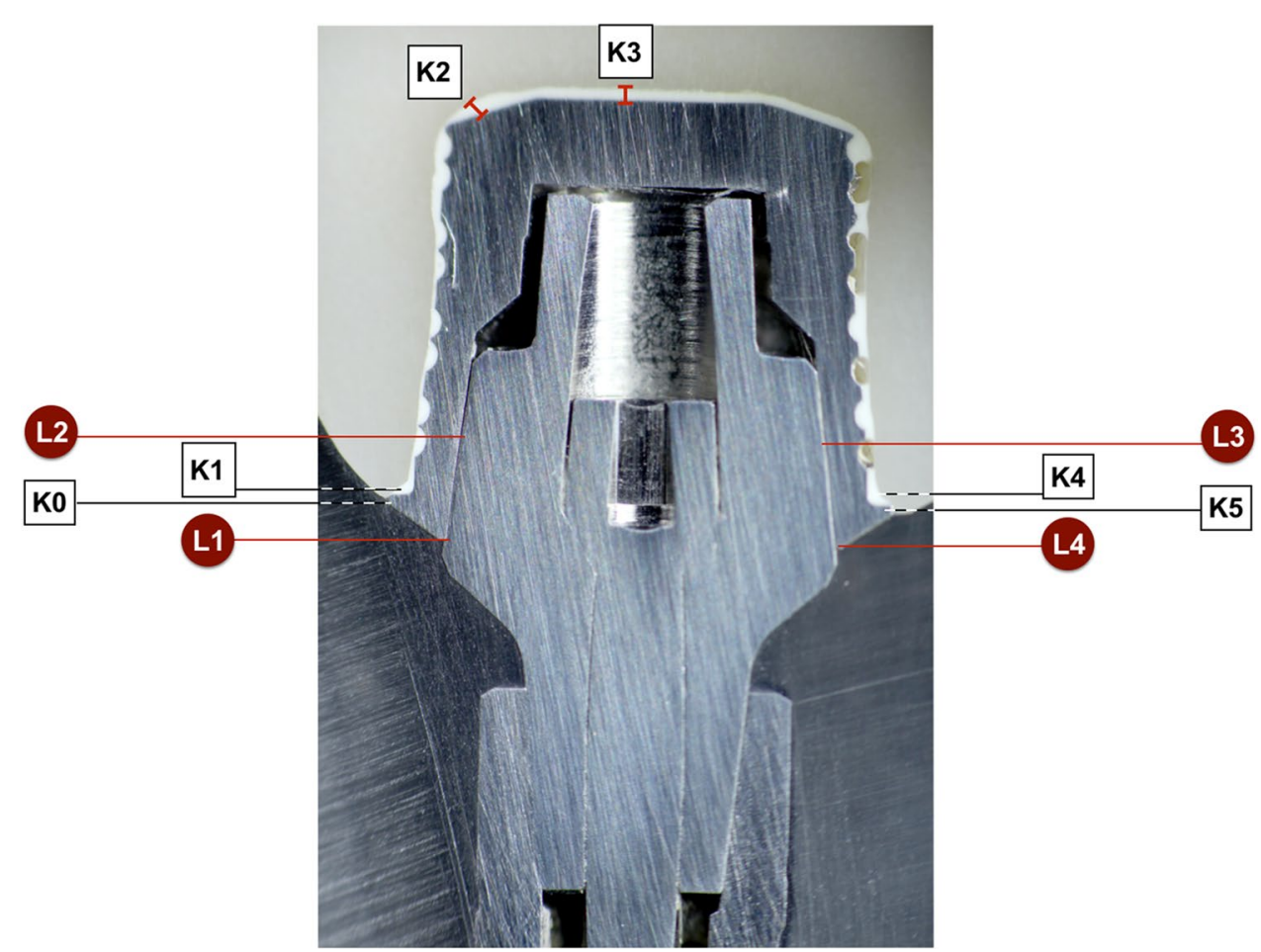


Table 3 Comparison of control and test groups demonstrated a significant difference of qrt-PCR results between positive control and test groups $(p<0.001)$, whereas no difference was found between negative control and test groups and between the three different dentals implant systems

Differences of Type / Least Squares Means

\begin{tabular}{|c|c|c|c|c|c|c|c|c|c|}
\hline Group & Group & Estimation & Standard Error & DF & t-Wert & $\operatorname{Pr}>|t|$ & Alpha & Lower & Upper \\
\hline Anklyos C/X & Astra Tech EV & 0.1207 & 0.1080 & 140 & 1.12 & 0.2653 & 0.05 & -0.09269 & 0.3342 \\
\hline Anklyos C/X & Negative Control & 0.07961 & 0.1986 & 140 & 0.40 & 0.6891 & 0.05 & -0.3130 & 0.4722 \\
\hline Anklyos C/X & Xive S plus & -0.1330 & 0.1080 & 140 & -1.23 & 0.2200 & 0.05 & -0.3464 & 0.08043 \\
\hline Anklyos C/X & Positive Control & -4.3264 & 0.1347 & 140 & -32.13 & $<.0001$ & 0.05 & -4.5927 & -4.0602 \\
\hline Astra Tech EV & Negative Control & -0.04114 & 0.1986 & 140 & -0.21 & 0.8361 & 0.05 & -0.4337 & 0.3514 \\
\hline Astra Tech EV & Xive S plus & -0.2538 & 0.1080 & 140 & -2.35 & 0.0201 & 0.05 & -0.4672 & -0.04032 \\
\hline Astra Tech EV & Positive Control & -4.4472 & 0.1347 & 140 & -33.02 & $<.0001$ & 0.05 & -4.7134 & -4.1809 \\
\hline Negative Control & Xive S plus & -0.2126 & 0.1986 & 140 & -1.07 & 0.2861 & 0.05 & -0.6052 & 0.1799 \\
\hline Negative Control & Positive Control & -4.4060 & 0.2137 & 140 & -20.61 & $<.0001$ & 0.05 & -4.8286 & -3.9834 \\
\hline Xive S plus & Positive Control & -4.1934 & 0.1347 & 140 & -31.14 & $<.0001$ & 0.05 & -4.4597 & -3.9272 \\
\hline
\end{tabular}

Fig. 5 Graphical illustration of statistical results for total bacterial exit. A significant difference of qrt-PCR results between positive control and all three test groups could be demonstrated $(p<0.0001)$. No difference between negative control and all three test groups could be shown

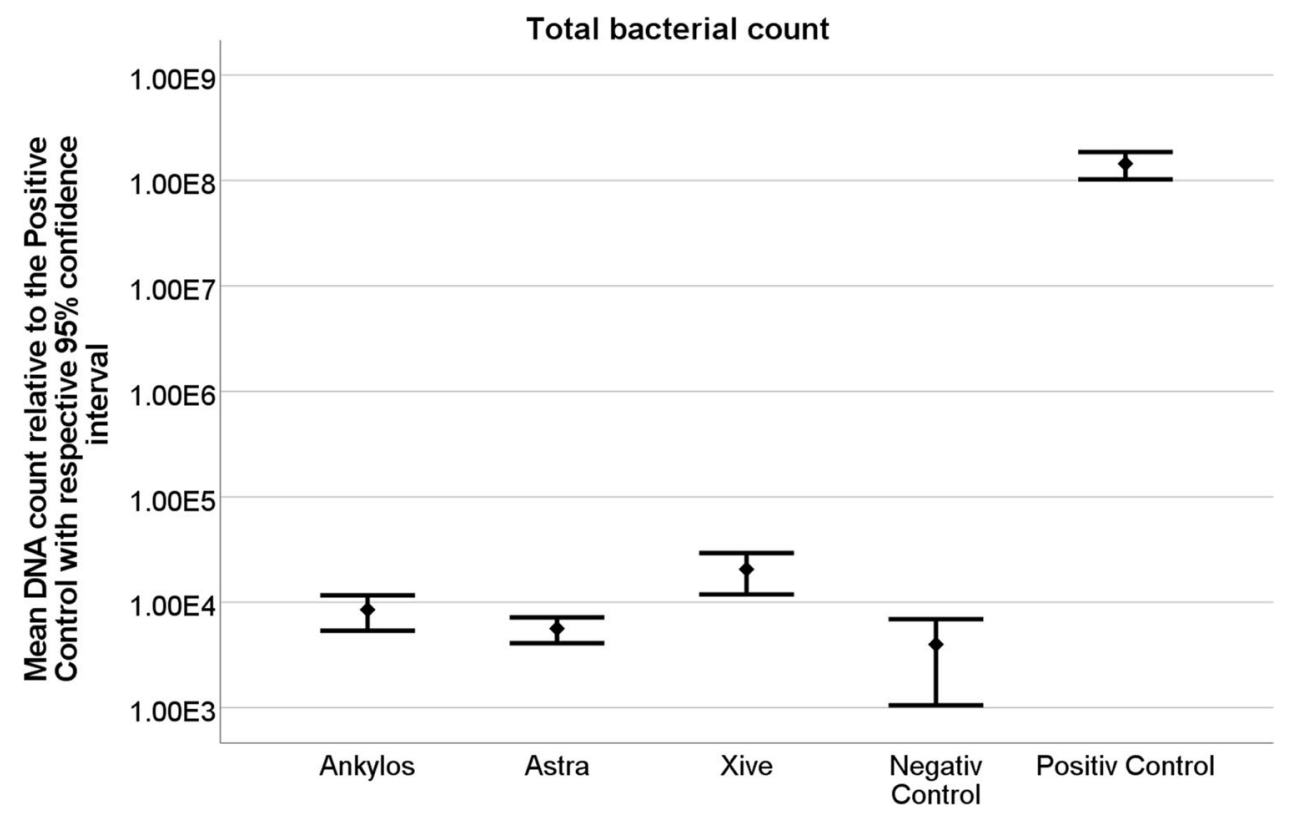

the different test days yielded a significant difference $(p<0.0001)$, although not of clinical relevance (Table 4).

\section{Bacterial ingrowth}

Also, the qrt-PCR results for potential bacterial entry into the conometric system remained negative for all specific primers tested on all three implant systems and were significantly different from the positive control $(p<0.0001)$ (Fig. 6).

\section{SEM readings of microgap dimensions of conometric connection}

Despite the planar contact along the cone-in-cone interface, miniscule punctate microgaps could be recorded in SEM analysis at the predefined reference sites L1 to L4 of the conometric connection. The mean external microgap for all abutment specimens averaged $2.04 \pm 1.67 \mu \mathrm{m}$ (min. $0.83 \mu \mathrm{m} /$ $\max .7 .43 \mu \mathrm{m}$ ) at the landmarks L1 and $2.64 \pm 3.1 \mu \mathrm{m}$ (min. $0.72 \mu \mathrm{m} / \mathrm{max} .11 .8 \mu \mathrm{m}$ ) at the contralateral reference sites

Table 4 Comparison of test and control group had a significant effect on the results of bacterial growth $(p<0.001)$. A significant difference for mean bacterial count on different test days was observed

Type III test of effects

\begin{tabular}{lllll}
\hline Effect & No. DF & Den DF & F-value & $\operatorname{Pr}>$ F \\
\hline Type & 4 & 140 & 332.65 & $<.0001$ \\
Day & 1 & 140 & 40.72 & $<.0001$ \\
\hline
\end{tabular}


Fig. 6 Graphical illustration of the statistical results for total bacterial entry. While a significant difference in qrt-PCR results was shown between the positive control and all three test groups $(p<0.0001)$, no difference could be detected between the negative control and the test groups

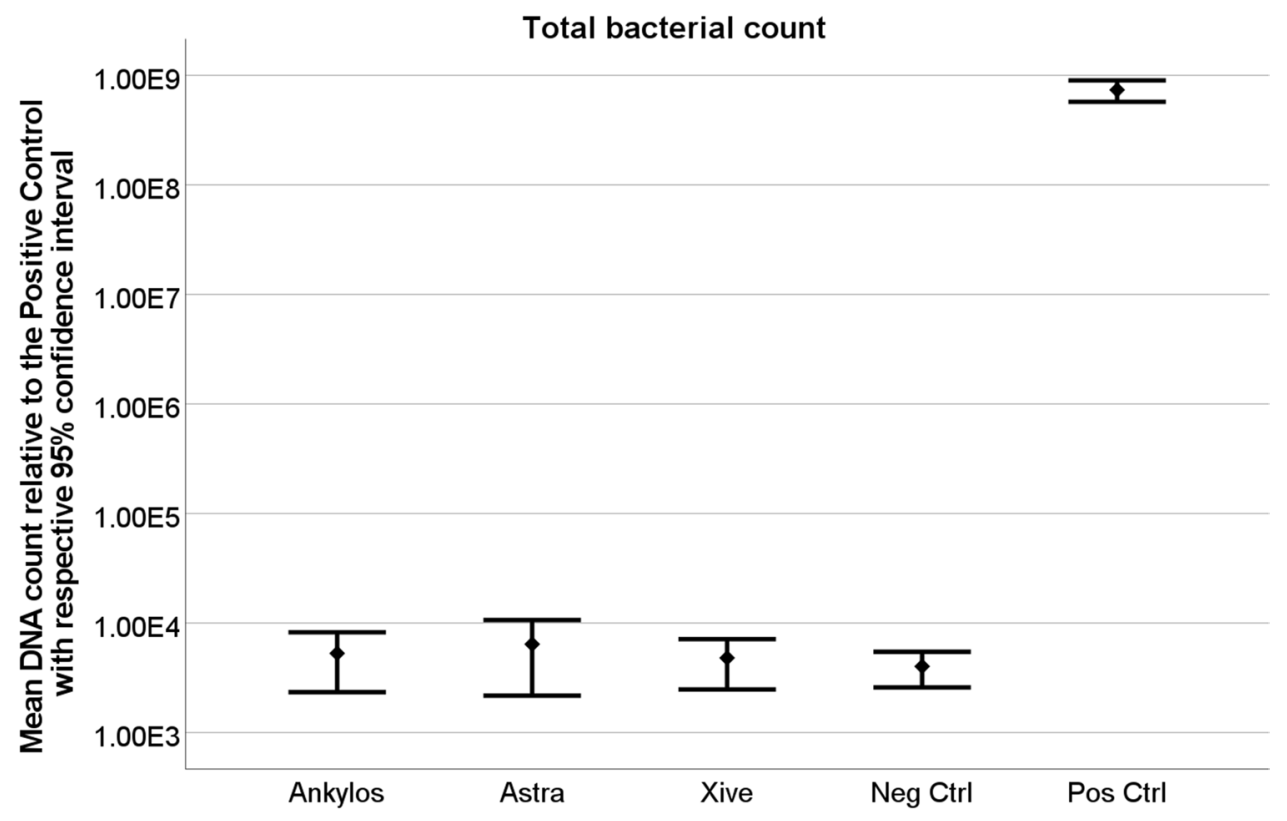

L4 (Table 5). The internal mid-vertical microgaps L2 and L3 reached a mean value of $2.64 \pm 2.22 \mu \mathrm{m}$ (min. $0.74 \mu \mathrm{m} /$ $\max .7 .67 \mu \mathrm{m})$ and $3.67 \pm 2.28 \mu \mathrm{m}(\min .0 .81 \mu \mathrm{m} / \mathrm{max}$. 7.67 ), respectively. When comparing the three systems, there was no significant difference in the microgap size of the respective landmark investigated (Kruskal-Wallis $p>0.05$ ). Table 6 and Fig. 7 list the mean microgap dimensions of all conometric connections at four reference sites for each system individually and collectively. Figure 8 shows exemplary SEM images at landmarks L1 to L4 of the three systems examined at $1000 \times$ magnification.

\section{SEM readings of cement gap dimensions of crown-coping complex}

The mean marginal opening of the all-ceramic crowns at the reference points $\mathrm{K} 0$ and $\mathrm{K} 5$ measured $11.7 \pm 5.93 \mu \mathrm{m}$ (min. $5.25 \mu \mathrm{m} / \max .22 .8 \mu \mathrm{m}$ ) for all samples, while the internal cement gap widths amounted to $135 \pm 14.6 \mu \mathrm{m}$ (min. $96.8 \mu \mathrm{m} /$ $\max .156 \mu \mathrm{m}$ ) for landmarks $\mathrm{K} 1$ and $\mathrm{K} 4$ and $145 \pm 84.5 \mu \mathrm{m}$ (min. $83.3 \mu \mathrm{m} / \max .423 \mu \mathrm{m}$ ) for $\mathrm{K} 2$ and $\mathrm{K} 3$, respectively

Table 5 Overall mean values of gap dimensions at the conometric reference sites (L1-L4) for all specimens tested (total $n=15$ ), standard deviation, median, minimum, and maximum

\begin{tabular}{lllllc}
\hline Location & Mean & SD & Median & Min & Max \\
\hline Microgap L1 & 2.04 & 1.67 & 1.52 & 0.826 & 7.43 \\
Microgap L2 & 2.64 & 2.22 & 1.98 & 0.744 & 7.67 \\
Microgap L3 & 3.67 & 2.28 & 3.35 & 0.805 & 7.67 \\
Microgap L4 & 2.64 & 3.1 & 1.48 & 0.716 & 11.8 \\
Mean all L & 2.75 & 1.44 & 2.24 & 0.918 & 5.84 \\
\hline
\end{tabular}

(Table 7). Despite the evident differences between the mean external (K0 and $\mathrm{K} 5$ ) and internal microgaps (K1 to K4) $\left(\mathrm{Chi}^{2}=24.1 ; p<0.001\right)$, none of the implant systems showed systematically higher or lower values than the other groups (Fig. 9). The measured cement gap dimensions of all 15 specimens at six reference points for each individual system are shown in Table 8. A comparison among the respective crown coping landmarks $\mathrm{K} 0$ to $\mathrm{K} 5$ of the three implant abutment systems showed no statistically significant difference with respect to the mean cement gap (Kruskal-Wallis $p>0.05$ ). Figure 10 shows exemplary SEM images of cement gap measurements and marginal integrity of the ceramic crowns on the cemented Acuris copings at $200 \times$ magnification.

\section{Discussion}

In an effort to minimize inflammatory responses and thereby maximize bone stability around the implant platform, numerous in vivo and in vitro studies have demonstrated

Table 6 Mean microgap dimensions, standard deviation, and statistical significance of all conometric connections at four reference sites (L1-L4) for each system individually and collectively

\begin{tabular}{lccll}
\hline & $\begin{array}{l}\text { Ankylos C/X } \\
(n=5)\end{array}$ & $\begin{array}{l}\text { Astra Tech EV } \\
(n=5)\end{array}$ & $\begin{array}{l}\text { Xive S plus } \\
(n=5)\end{array}$ & Test \\
\hline Location & Mean \pm SD & Mean \pm SD & Mean \pm SD & $p$ value \\
Microgap L1 & $2.09 \pm 0.92$ & $1.50 \pm 0.638$ & $2.54 \pm 2.79$ & 0.619 \\
Microgap L2 & $3.56 \pm 1.99$ & $1.12 \pm 0.294$ & $3.24 \pm 2.96$ & 0.065 \\
Microgap L3 & $3.89 \pm 3.25$ & $3.80 \pm 1.81$ & $3.33 \pm 2.02$ & 0.932 \\
Microgap L4 & $1.55 \pm 0.58$ & $4.99 \pm 4.74$ & $1.38 \pm 0,69$ & 0.310 \\
Mean all L & $2.77 \pm 1.23$ & $2.85 \pm 1.42$ & $2.62 \pm 1.93$ & 0.827 \\
\hline
\end{tabular}




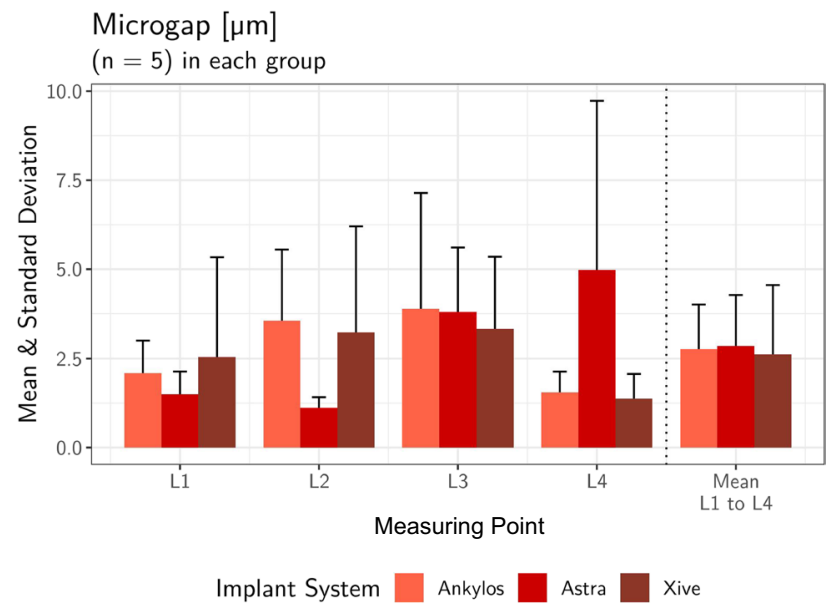

Fig. 7 Bar graph of the recorded mean conometric microgap dimensions at landmarks L1-L4 for each individual system and total value

the influence of the implant-abutment (I-A) microgap on marginal leakage [15-24]. This is in contrast to the limited data available on the fit and potential for microbial leakage at conometric prosthetic connections [7, 10], Clinical evidence of bacterial sealing of the taper coupling at the restorative level is lacking to date. Marginal and internal fit at the abutment-prosthesis interface are critical determinants as they are directly related to bio-integrity, microbial sealing, and maintenance of peri-implant tissue health [25]. As a consequence, the current in vitro study investigated the presence of microgap formation and bacterial translocation at the cone-in-cone interface of three different implant abutment systems for single crown restoration. In addition, the internal fit and marginal integrity of all-ceramic crowns on the matching tapered copings were determined.

The qrt-PCR results of the microbiological tests indicate that the Acuris conometric interface of all three implant systems investigated does not allow for bacterial translocation under unloaded conditions. None of the systems studied (Ankylos C/X, Astra Tech EV, Xive S plus) exhibited any significant bacterial leakage into or out of the conometric junction. Thus, the hypothesis that the Acuris coupling precludes bacterial translocation irrespective of the implant system type can be regarded as accepted. In terms
Fig. 8 Exemplary SEM images of the three systems examined at $1000 \times$ magnification, showing the punctuate microgaps of the conometric connection at landmarks L1 to L4. Reference points L1 and L4 refer to the apically located areas of the coping margin (external gaps). Landmarks L2 and L3 represent the mid-vertical taper of the Acuris abutment (internal gaps)
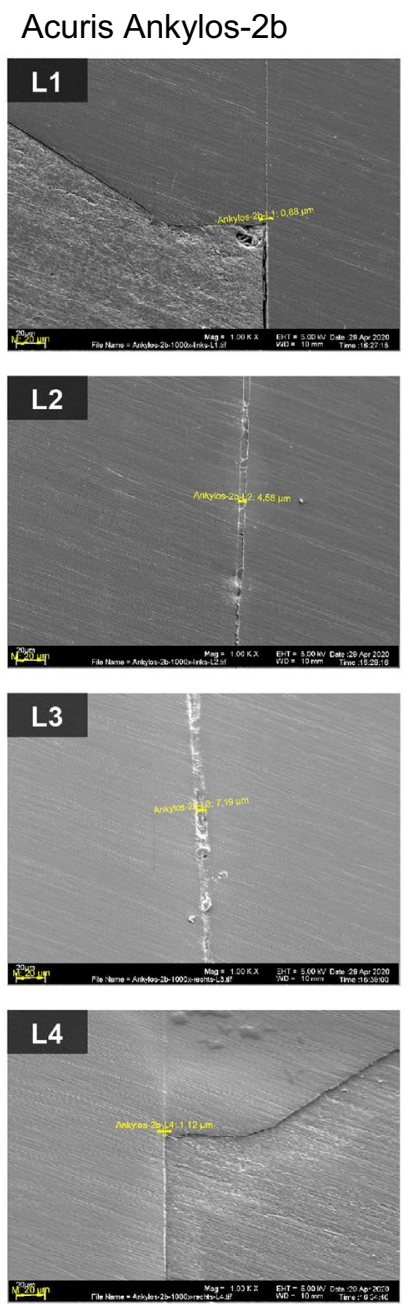

Acuris Astra EV-2a
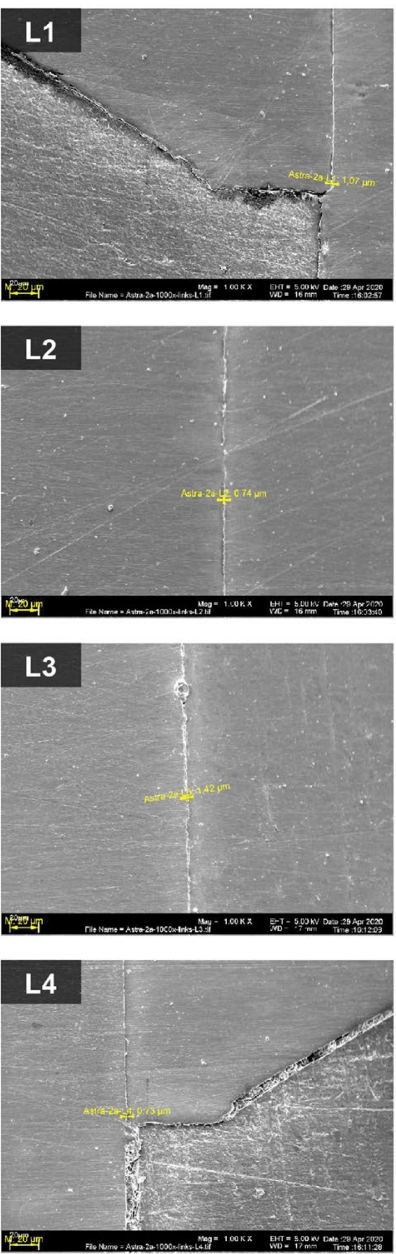

Acuris Xive-2b
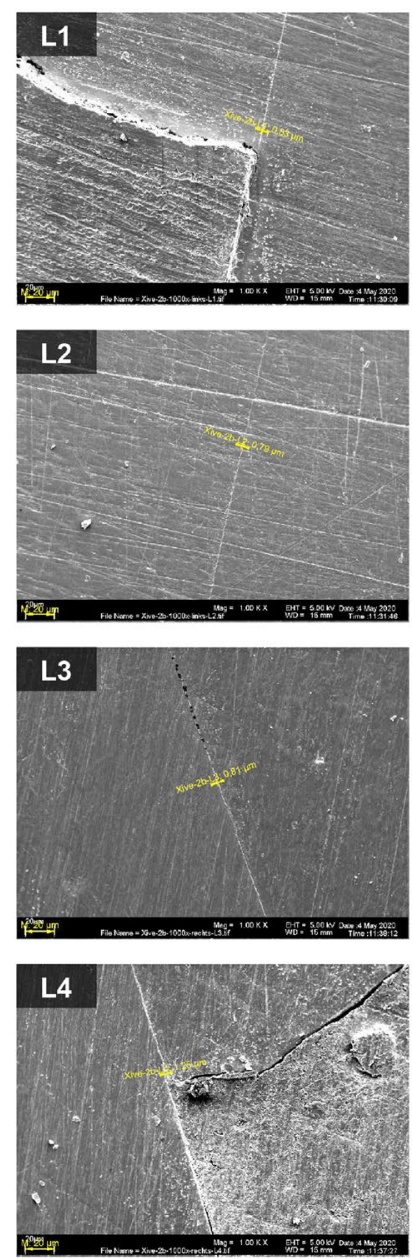
Table 7 Overall mean values of cement gap sizes (K0-K5) for all specimens tested (total $n=15$ ), standard deviation, median, minimum, and maximum

\begin{tabular}{llllll}
\hline Location & Mean & SD & Median & Min & Max \\
\hline Microgap K0 & 11.4 & 6.66 & 11 & 3.91 & 24.1 \\
Microgap K1 & 134 & 25.6 & 137 & 56.5 & 167 \\
Microgap K2 & 148 & 75.4 & 127 & 37.8 & 293 \\
Microgap K3 & 142 & 119 & 118 & 84 & 570 \\
Microgap K4 & 136 & 13.3 & 134 & 114 & 161 \\
Microgap K5 & 12.1 & 5.69 & 10.3 & 5.3 & 21.6 \\
Mean K0 \& K5 & 11.7 & 5.93 & 10.7 & 5.25 & 22.8 \\
Mean K1 \& K4 & 135 & 14.6 & 135 & 96.8 & 156 \\
Mean K2 \& K3 & 145 & 84.5 & 122 & 83.3 & 423 \\
Mean all K & 97.2 & 29.7 & 87.5 & 76.1 & 191 \\
\hline
\end{tabular}

of methodology, the application of qrt-PCR has been previously proven to be an accurate screening tool with a high diagnostic sensitivity for the determination of microbial migration in a pilot study by the authors [10]. Providing consistent positive and negative controls through both directions of the assay setup rendered reliable results. The testing period for bidirectional bacterial translocation was 7 days. Longer observation periods are discouraged due to an increase in false negative findings [26]. The four most common representatives of the oral microbiome (Streptococcus mutans, Actinomyces naeslundii, Fusobacterium nucleatum, Porphyromonas gingivalis) were included in the tested bacterial mixed cultures. These bacteria are facultative pathogens and are associated with caries, mucositis, periodontitis, and peri-implantitis [27]. Setting parameters of the cultures were guided by the German Collection of Microorganisms and Cell Cultures (Leibniz Institute DSMZ,

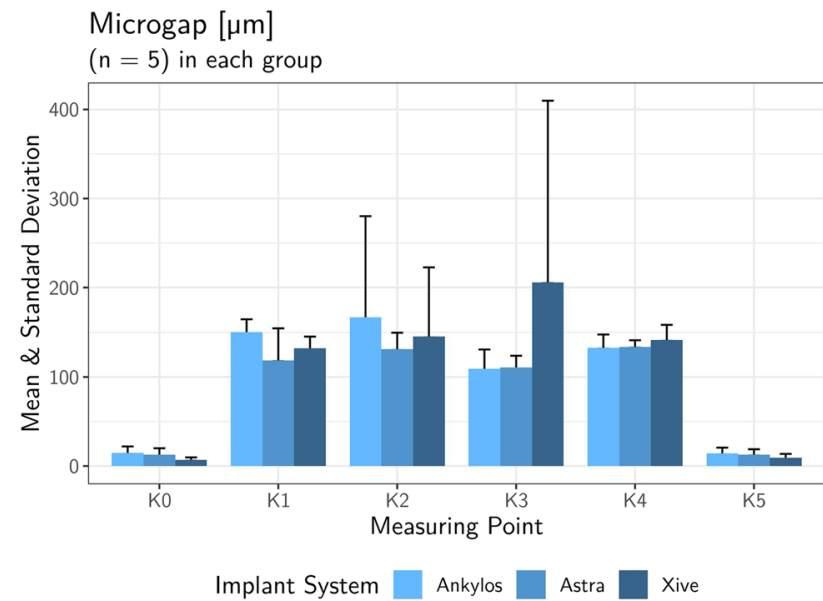

Fig. 9 Bar graph of the mean external (K0/K5) and internal crowncoping cement gaps $(\mathrm{K} 1-\mathrm{K} 4)$ of the three groups of implant-abutment systems
Table 8 Comparison of the three implant-abutment systems in terms of mean cement gap widths, standard deviation and statistical significance at all six measuring landmarks (K0 to K5) for each system tested

\begin{tabular}{|c|c|c|c|c|}
\hline & $\begin{array}{l}\text { Ankylos C/X } \\
(n=5)\end{array}$ & $\begin{array}{l}\text { Astra Tech EV } \\
(n=5)\end{array}$ & $\begin{array}{l}\text { Xive S plus } \\
(n=5)\end{array}$ & Test \\
\hline Location & Mean \pm SD & Mean \pm SD & Mean $\pm S D$ & $p$ value \\
\hline Gap K0 & $14.7 \pm 7.33$ & $12.5 \pm 7.45$ & $6.99 \pm 2.68$ & 80.174 \\
\hline Gap K1 & $150 \pm 14.6$ & $119 \pm 35.9$ & $132 \pm 13.2$ & 0.141 \\
\hline Gap K2 & $167 \pm 113$ & $131 \pm 18.4$ & $146 \pm 77.1$ & 0.961 \\
\hline Gap K3 & $109 \pm 21.8$ & $111 \pm 13.4$ & $206 \pm 204$ & 0.619 \\
\hline Gap K4 & $133 \pm 14.9$ & $134 \pm 7.41$ & $142 \pm 16.9$ & 0.651 \\
\hline Gap K5 & $14.2 \pm 6.48$ & $12.8 \pm 6.01$ & $9.24 \pm 4.38$ & 80.392 \\
\hline
\end{tabular}

Braunschweig, Germany). The culture medium was renewed every $48 \mathrm{~h}$ to ensure optimal conditions for bacterial growth as described in previous studies [12]. Adequate bacterial growth environment was confirmed by positive qrt-PCR results for each positive control at all time points. Given the results of the bacterial assays, the principal acceptance that sealing and retention of morse taper connections are achieved by wedge action $[17,23]$ may also be applied to the sealing efficiency of conometrically seated prosthetic components at the abutment-coping interface. In this context, it is important to note that the friction-based tapered coupling requires a fully seated matrix on the abutment. Incorrectly mounted conometric components will cause poor sealing and may present a risk for bacterial leakage. Within a clinical setting, incomplete retention of the crown-coping-unit would induce occlusal disturbances, a friction deficit, and instantaneous dislocation of the crown. Causes for clinically inferior crown fit and insufficient retention may include tight proximal contacts or a pronounced emergence profile design of the soft tissues.

A secondary objective of the study was to optically determine the fit of the conometric coupling as well as the internal fit and marginal integrity of cemented CAD/CAM crowns on the matching Acuris TiN copings by means of SEM. Despite the fact that the comprehensive microbiological examination in a double verification setup failed to demonstrate microbial leakage from or into the Acuris abutment system, SEM analysis was able to detect minute punctate microgaps at predefined reference sites of the conometric connection. The mean outer microgap for all abutment specimens clinically positioned just within the peri-implant sulcus was 2.04 and $2.64 \mu \mathrm{m}$, respectively. The inner mid-vertical microgaps reached a mean value of 2.64 and $3.67 \mu \mathrm{m}$, depending on the measuring point. When comparing the respective measuring points, no significant difference in the microgap dimensions between the systems could be detected. The first part of the null hypothesis, which stated that the conometric interface exhibits no detectable microgap microscopically, could thus 
Fig. 10 Exemplary SEM images showing the measurements for cement gap and marginal integrity of the ceramic crowns on cemented Acuris copings at reference points $\mathrm{K} 0$ to $\mathrm{K} 5$. Landmarks $\mathrm{K} 0$ and $\mathrm{K} 5$ determine the marginal discrepancy of the crown and the coping after cementation at $1000 \times$ magnification. Landmarks K1 to $\mathrm{K} 4$ represent the vertical and horizontal luting gaps inside the crown at $200 \times$ magnification
TiN/Crown on Ankylos-3b
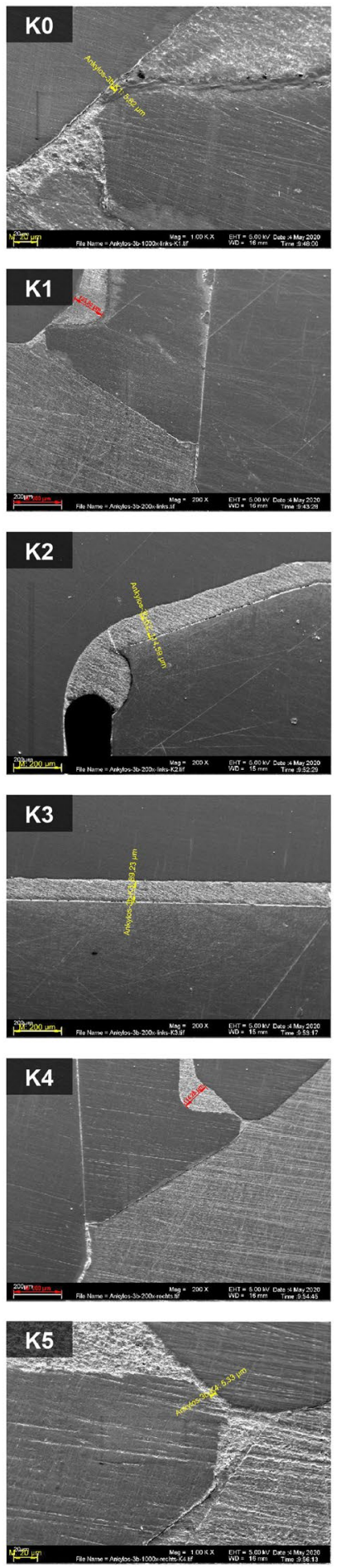

TiN/Crown on Astra EV- 2b
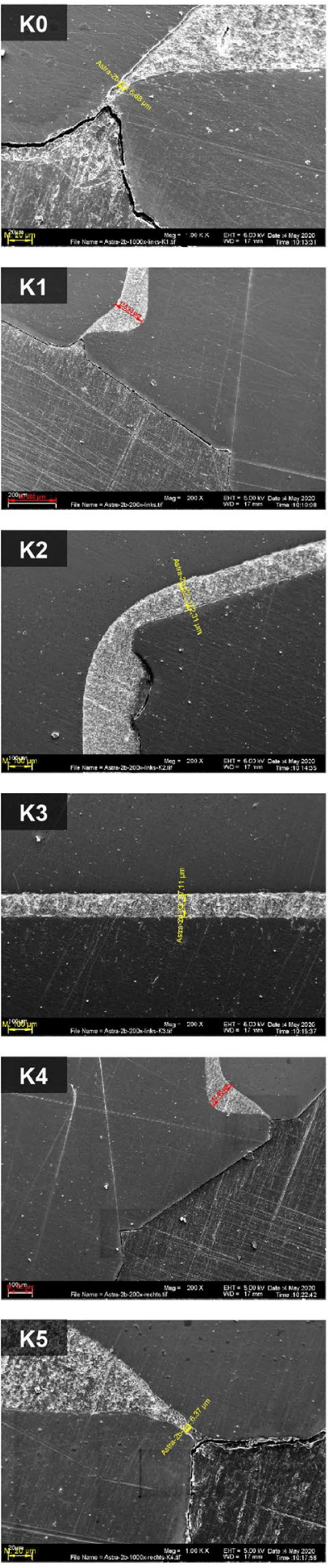

TiN/Crown on Xive-3b
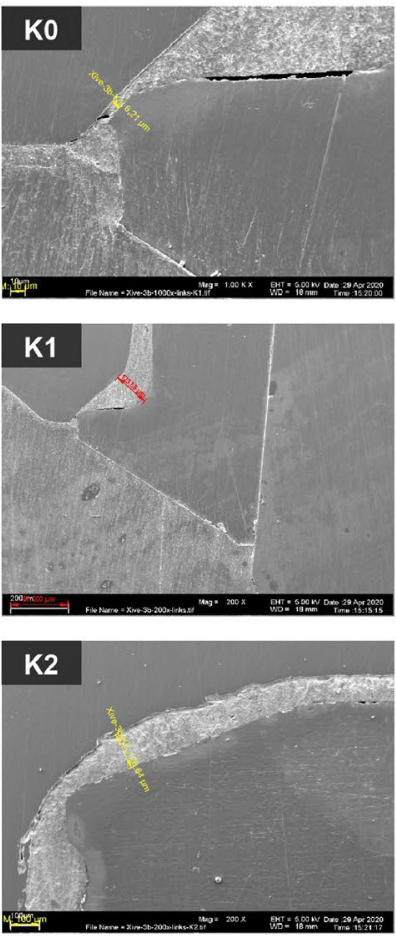

K3

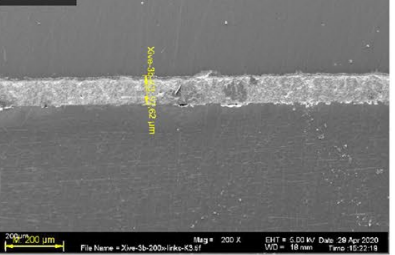

K4

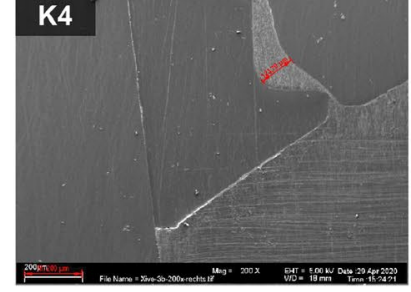

K5

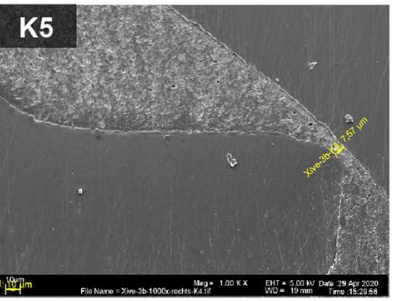

be considered rejected. In contrast to the minimal punctual gaps of the conometric joint, considerably larger cement gaps were observed at the restorative interface between the crown and the Acuris TiN coping. Whereas the marginal opening of the CAD/CAM ceramic crowns averaged $12 \mu \mathrm{m}$ for all specimens, the mean value for the internal cement gap was as high as $145 \mu \mathrm{m}$. The present results confirm the findings of 3D evaluations demonstrating enlarged internal spaces at the angles of milled restorations. This phenomenon may be related to constraints in milling precision caused by the size of the milling burs [28, 29]. Despite the obvious differences between marginal deficiencies and inner microgaps, 
none of the tested implant systems exhibited a significant difference with respect to the mean cement gap. Thus, the second part of the null hypothesis, which postulated no difference in internal fit and marginal integrity between the tested systems, could not be rejected.

While the importance of internal crown fit and, in particular, its marginal integrity is generally agreed upon in terms of clinical survival and restoration quality, views on the clinical relevance of the magnitude of marginal discrepancies are controversial. The marginal fit of conventionally fabricated all-ceramic crowns was found to range from 30 to $160 \mu \mathrm{m}$ [30-32]. Substantial marginal discrepancy in cemented restorations increases the layer thickness of the luting material exposed to oral fluids, which in turn may result in cement dissolution and marginal leakage. The difficulty of removing excess cement when the marginal gap exceeds $100 \mu \mathrm{m}$ has been pointed out in some studies [33]. Wolfart et al. reported a significant increase in the median marginal deviation of pressed lithium disilicate crowns from 96 to $130 \mu \mathrm{m}$ due to cementation [34]. Inadequate marginal adaptation increases plaque accumulation and alters the distribution of microbiota, leading to inflammation of periodontal tissues around teeth and periimplant infections around implants [25, 35, 36]. Bone loss and ultimate breakdown of osseointegration may occur and be responsible for clinical failure of fixed implant restorations [37]. The precision of fit of a restoration also affects the long-term stability of all-ceramic crowns [38, 39]. A causal relationship between increased cement thickness and reduced bending strength of ceramics has been documented [40, 41]. Restorations manufactured by computeraided design/computer-assisted manufacturing (CAD/ CAM) techniques displayed marginal discrepancies less than $100 \mu \mathrm{m}[42,43]$ and improved marginal integrity [30, 44]. These findings are in agreement with the results of the current study for internal fit of the crown and its marginal discrepancies. However, for a comparison, the different materials, measurement methods, and restoration types (FPDs vs. SCs) must be taken into account. Despite the fact that a digitally assisted fabrication process enhances the fit of all-ceramic frameworks, microscopic evidence indicates that a gap and correlating misfit between the ceramic crown and its respective abutment cannot be fully avoided [28, 29, 45]. In this regard, it should be noted that the marginal gap widths for all-ceramic restorations increase proportionally to the final curvature line, irrespective of the ceramic material [46].

Overall, the methods used for sample production and evaluation should provide a realistic representation of the clinical situation in the fixation of conometric morse taper connections for the retention of implant-supported single crowns (SCs). A limitation associated with the SEM analysis was that the landmarks selected for gap measurements may not have been truly representative for the overall fit of the components. Since a complete measurement over the entire interface area was neither practical nor reasonable, the data obtained can, however, be considered representative. A further constraint of the present study relates to the conflicting findings regarding the complete seal against micro-leakage, on the one hand, and the evidence of punctiform gap formations at the conical interface of the morse-taper junction on the other hand. The reason for this fact may be due to the particular design of the Acuris connection. Unlike conventional conical connections, where the joint surfaces contact each other in a full planar configuration, the Acuris conometric connection is designed in such a way that it has two counter bearings. An annular mating surface (first counter bearing) is provided at the opening area of the TiN coping. The contact zone between the abutment index and the coping has a cylindrical contact surface that acts as a second counter bearing. The ring-shaped mating surface is designed to prevent bacterial translocation, while the cylindrical pressure of the mounting surface provides resistance to shear forces during masticatory movements. A flat contact surface along the entire taper is deliberately omitted, as the removal forces would consequently be difficult to adjust or to control clinically. The SEM images of the present analysis reflect this engineering principle under the current conditions of use (Fig. 4). The matrix material of the titanium nitride copings comprises grade 4 titanium, while the Acuris abutment itself is made of a grade 5 titanium alloy (Ti 6Al-4 V ELI). Due to the required grinding and preparation processes of the specimens for SEM analysis, manufacturing-related smearing of the softer TiN coping material may have occurred at the interface. Despite adherence to high-quality precautions, it cannot be completely ruled out that possible miniature artifacts were misinterpreted as microgaps during SEM evaluation. To put the relevance of the obtained in vitro results into a clinical perspective, further studies are needed to determine the long-term outcome of peri-implant tissue health of conometrically seated SCs.

\section{Conclusions}

Within the limitations of the present bidirectional in vitro study, no bacterial leakage from or into the Acuris abutment of 3 different implant systems could be detected upon microbiological examination. SEM analysis revealed tiny punctate microgaps at the most apical point of the conometric connection with an average width of 2 to $3 \mu \mathrm{m}$ for all systems tested. Considerably larger cement gaps were observed at the restorative interface between the all-ceramic crown and the matching Acuris TiN coping. The marginal discrepancies of the CAD/CAM crowns averaged $12 \mu \mathrm{m}$ across all specimens, while the mean value for the internal cement gap amounted for up to $145 \mu \mathrm{m}$. 
Acknowledgements The authors gratefully acknowledge Jürgen GeisGerstorfer for his valuable input to the microscopic test concept. We thank Frank Fischer for his technical assistance, Alexander Georgitsis, and Steffen Greßbach for their assistance in data collection and Wolfgang Reimers for his contribution to data analysis and statistical support. The authors thank DENTSPLY Sirona Implants, Mölndal, Sweden, for providing the test samples for the experimental investigation.

Author contributions Gehrke P: Idea; concept; design; data collection; data analysis; interpretation; drafted the manuscript.

Burg S: Bacterial analysis; data collection; interpretation; drafted the manuscript.

Peters U: Data collection, data analysis/interpretation.

Beikler T: Critical revision and approval of the article.

Fischer C: Fabrication of specimens for SEM analysis.

Rupp F: Critical revision and approval of the article.

Schweizer E: SEM analysis and data collection.

Weigl P: Interpretation and critical revision.

Sader R: Critical revision and approval of the article.

Smeets R: Interpretation and critical revision.

Schäfer S: Bacterial analysis; data collection; interpretation; drafted the manuscript.

Funding Open Access funding enabled and organized by Projekt DEAL.

\section{Declarations}

Ethics approval This article does not contain any studies with human participants or animals performed by any of the authors.

Informed consent For this type of study, formal consent is not required.

Conflict of interest The authors declare that they have no conflict of interest. Dentsply Sirona Implants, Mölndal, Sweden, provided the specimens for the experimental investigation. The design, documentation, and analyses of this study were completed entirely independent of Dentsply Sirona Implants.

Open Access This article is licensed under a Creative Commons Attribution 4.0 International License, which permits use, sharing, adaptation, distribution and reproduction in any medium or format, as long as you give appropriate credit to the original author(s) and the source, provide a link to the Creative Commons licence, and indicate if changes were made. The images or other third party material in this article are included in the article's Creative Commons licence, unless indicated otherwise in a credit line to the material. If material is not included in the article's Creative Commons licence and your intended use is not permitted by statutory regulation or exceeds the permitted use, you will need to obtain permission directly from the copyright holder. To view a copy of this licence, visit http://creativecommons.org/licenses/by/4.0/.

\section{References}

1. Bressan E, Sbricoli L, Guazzo R, Bambace M, Lops D, Tomasi C (2019) Five-year prospective study on conometric retention for complete fixed prostheses. Int J Oral Implantol (Berl) 12:105-113

2. Degidi M, Nardi D, Gianluca S, Piattelli A (2018) The conometric concept: a 5-year follow-up of fixed partial monolithic zirconia restorations supported by cone-in-cone abutments. Int J Periodontics Restorative Dent 38:363-371. https://doi.org/10. 11607/prd.3130
3. Degidi M, Nardi D, Sighinolfi G, Degidi D (2020) The conometric concept for the definitive rehabilitation of a single posterior implant by using a conical indexed abutment: A technique. J Prosthet Dent 123:576-579. https://doi.org/10.1016/j.prosdent. 2019.02.020

4. Albiero AM, Benato R, Momic S, Degidi M (2021) Computeraided crown design using digital scanning technology for immediate postextraction single-implant restorations supported by conical indexed abutments. Int J Periodontics Restorative Dent 41:135-140. https://doi.org/10.11607/prd.4955

5. Degidi M, Nardi D, Sighinolfi G, Degidi D, Piattelli A (2019) The conometric concept: a two-year follow-up of fixed partial CEREC restorations supported by cone-in-cone abutments. J Prosthodont 28:e780-e787. https://doi.org/10.1111/jopr.12962

6. Degidi M, Nardi D, Sighinolfi G, Piattelli A (2018) The conometric concept: definitive fixed lithium disilicate restorations supported by conical abutments. J Prosthodont 27:605-610. https://doi.org/10.1111/jopr.12548

7. Bressan E, Stocchero M, Jimbo R, Rosati C, Fanti E, Tomasi C, Lops D (2017) Microbial leakage at morse taper conometric prosthetic connection: an in vitro investigation. Implant Dent 26:756-761. https://doi.org/10.1097/ID.0000000000000657

8. Kotsakis GA, Olmedo DG (2021) Peri-implantitis is not periodontitis: Scientific discoveries shed light on microbiome-biomaterial interactions that may determine disease phenotype. Periodontol 2000 86:231-240. https://doi.org/10.1111/prd. 12372

9. Carinci F, Romanos GE, Scapoli L (2019) Molecular tools for preventing and improving diagnosis of peri-implant diseases. Periodontol 2000 81:41-47. https://doi.org/10.1111/prd.12281

10. Gehrke P, Hartjen P, Smeets R, Gosau M, Peters U, Beikler T, Fischer C, Stolzer C, Geis-Gerstorfer J, Weigl P, Schafer S (2021) Marginal adaptation and microbial leakage at conometric prosthetic connections for implant-supported single crowns: an in vitro investigation. Int J Mol Sci 22. https://doi.org/10.3390/ ijms22020881

11. Murray PRRK, Pfaller MA (2020) Bacteriology, Section 4. Book title, 9th edn. Elsevier/Saunders, Philadelphia

12. Carrouel F, Viennot S, Santamaria J, Veber P, Bourgeois D (2016) Quantitative molecular detection of 19 major pathogens in the Interdental biofilm of periodontally healthy young adults. Front Microbiol 7:840. https://doi.org/10.3389/fmicb.2016.00840

13. Hoshino T, Kawaguchi M, Shimizu N, Hoshino N, Ooshima T, Fujiwara T (2004) PCR detection and identification of oral streptococci in saliva samples using gtf genes. Diagn Microbiol Infect Dis 48:195-199. https://doi.org/10.1016/j.diagmicrobio.2003.10. 002

14. Bizhang M, Ellerbrock B, Preza D, Raab W, Singh P, Beikler T, Henrich B, Zimmer S (2011) Detection of nine microorganisms from the initial carious root lesions using a TaqMan-based realtime PCR. Oral Dis 17:642-652. https://doi.org/10.1111/j.16010825.2011.01815.x

15. Alves DCC, de Carvalho PSP, Elias CN, Vedovatto E, Martinez EF (2016) In vitro analysis of the microbiological sealing of tapered implants after mechanical cycling. Clin Oral Investig 20:2437-2445. https://doi.org/10.1007/s00784-016-1744-0

16. Smith NA, Turkyilmaz I (2014) Evaluation of the sealing capability of implants to titanium and zirconia abutments against Porphyromonas gingivalis, Prevotella intermedia, and Fusobacterium nucleatum under different screw torque values. J Prosthet Dent 112:561-567. https://doi.org/10.1016/j.prosdent.2013.11.010

17. Canullo L, Penarrocha-Oltra D, Soldini C, Mazzocco F, Penarrocha M, Covani U (2015) Microbiological assessment of the implant-abutment interface in different connections: cross-sectional study after 5 years of functional loading. Clin Oral Implants Res 26:426-434. https://doi.org/10.1111/clr.12383 
18. Zipprich H, Miatke S, Hmaidouch R, Lauer HC (2016) A new experimental design for bacterial microleakage investigation at the implant-abutment interface: an in vitro study. Int J Oral Maxillofac Implants 31:37-44. https://doi.org/10.11607/jomi.3713

19. Koutouzis T, Wallet S, Calderon N, Lundgren T (2011) Bacterial colonization of the implant-abutment interface using an in vitro dynamic loading model. J Periodontol 82:613-618. https://doi. org/10.1902/jop.2010.100415

20. Lopes de Chaves EMDEC, Sperandio M, Napimoga MH (2018) Association between implant-abutment microgap and implant circularity to bacterial leakage: an in vitro study using tapered connection implants. Int J Oral Maxillofac Implants 33:505-511. https://doi.org/10.11607/jomi.5836

21. Ozdiler A, Bakir-Topcuoglu N, Kulekci G, Isik-Ozkol G (2018) Effects of taper angle and sealant agents on bacterial leakage along the implant-abutment interface: an in vitro study under loaded conditions. Int J Oral Maxillofac Implants 33:1071-1077. https://doi.org/10.11607/jomi.6257

22. Assenza B, Tripodi D, Scarano A, Perrotti V, Piattelli A, Iezzi G, D'Ercole S (2012) Bacterial leakage in implants with different implant-abutment connections: an in vitro study. J Periodontol 83:491-497. https://doi.org/10.1902/jop.2011.110320

23. Lauritano D, Moreo G, Lucchese A, Viganoni C, Limongelli L, Carinci F (2020) The impact of implant-abutment connection on clinical outcomes and microbial colonization: a narrative review. Materials (Basel) 13. https://doi.org/10.3390/ma13051131

24. Tripodi D, D’Ercole S, Iaculli F, Piattelli A, Perrotti V, Iezzi G (2015) Degree of bacterial microleakage at the implant-abutment junction in cone morse tapered implants under loaded and unloaded conditions. J Appl Biomater Funct Mater 13:e367-e371. https://doi.org/10.5301/jabfm.5000247

25. Canullo L, Penarrocha M, Monje A, Catena A, Wang HL, Penarrocha D (2017) Association between clinical and microbiologic cluster profiles and peri-implantitis. Int J Oral Maxillofac Implants 32:1054-1064. https://doi.org/10.11607/jomi.6043

26. da Silva-Neto JP, Nobilo MA, Penatti MP, Simamoto PC Jr, das Neves FD, (2012) Influence of methodologic aspects on the results of implant-abutment interface microleakage tests: a critical review of in vitro studies. Int J Oral Maxillofac Implants 27:793-800

27. Sampaio-Maia B, Caldas IM, Pereira ML, Perez-Mongiovi D, Araujo R (2016) The Oral microbiome in health and its implication in oral and systemic diseases. Adv Appl Microbiol 97:171210. https://doi.org/10.1016/bs.aambs.2016.08.002

28. Alfaro DP, Ruse ND, Carvalho RM, Wyatt CC (2015) Assessment of the internal fit of lithium disilicate crowns using micro-CT. J Prosthodont 24:381-386. https://doi.org/10.1111/jopr.12274

29. Kim JH, Jeong JH, Lee JH, Cho HW (2016) Fit of lithium disilicate crowns fabricated from conventional and digital impressions assessed with micro-CT. J Prosthet Dent 116:551-557. https://doi. org/10.1016/j.prosdent.2016.03.028

30. Bindl A, Mormann WH (2005) Marginal and internal fit of allceramic CAD/CAM crown-copings on chamfer preparations. J Oral Rehabil 32:441-447. https://doi.org/10.1111/j.1365-2842. 2005.01446.x

31. Sulaiman F, Chai J, Jameson LM, Wozniak WT (1997) A comparison of the marginal fit of In-Ceram, IPS Empress, and Procera crowns. Int J Prosthodont 10:478-484

32. Halici SE, Hekimoglu C, Ersoy O (2018) Marginal fit of allceramic crowns before and after cementation: an in vitro study. Int J Periodontics Restorative Dent 38:e41-e48. https://doi.org/ $10.11607 / \mathrm{prd} .3169$
33. Kramer N, Lohbauer U, Frankenberger R (2000) Adhesive luting of indirect restorations. Am J Dent 13:60D-76D

34. Wolfart S, Wegner SM, Al-Halabi A, Kern M (2003) Clinical evaluation of marginal fit of a new experimental all-ceramic system before and after cementation. Int J Prosthodont 16:587-592

35. Canullo L, Tallarico M, Radovanovic S, Delibasic B, Covani U, Rakic M (2016) Distinguishing predictive profiles for patientbased risk assessment and diagnostics of plaque induced, surgically and prosthetically triggered peri-implantitis. Clin Oral Implants Res 27:1243-1250. https://doi.org/10.1111/clr.12738

36. Dalago HR, Schuldt Filho G, Rodrigues MA, Renvert S, Bianchini MA (2017) Risk indicators for peri-implantitis. a cross-sectional study with 916 implants. Clin Oral Implants Res 28:144-150. https://doi.org/10.1111/clr.12772

37. Sailer I, Balmer M, Husler J, Hammerle CHF, Kanel S, Thoma DS (2018) 10-year randomized trial (RCT) of zirconia-ceramic and metal-ceramic fixed dental prostheses. J Dent 76:32-39. https:// doi.org/10.1016/j.jdent.2018.05.015

38. Wettstein F, Sailer I, Roos M, Hammerle CH (2008) Clinical study of the internal gaps of zirconia and metal frameworks for fixed partial dentures. Eur J Oral Sci 116:272-279. https://doi.org/10. 1111/j.1600-0722.2008.00527.x

39. Federlin M, Krifka S, Herpich M, Hiller KA, Schmalz G (2007) Partial ceramic crowns: influence of ceramic thickness, preparation design and luting material on fracture resistance and marginal integrity in vitro. Oper Dent 32:251-260. https://doi.org/10.2341/ 06-70

40. Anusavice KJ, Jadaan OM, Esquivel-Upshaw JF (2013) Timedependent fracture probability of bilayer, lithium-disilicate-based, glass-ceramic, molar crowns as a function of core/veneer thickness ratio and load orientation. Dent Mater 29:1132-1138. https:// doi.org/10.1016/j.dental.2013.08.206

41. Thompson VP, Rekow DE (2004) Dental ceramics and the molar crown testing ground. J Appl Oral Sci 12:26-36. https://doi.org/ 10.1590/s1678-77572004000500004

42. Nakamura T, Dei N, Kojima T, Wakabayashi K (2003) Marginal and internal fit of Cerec 3 CAD/CAM all-ceramic crowns. Int J Prosthodont 16:244-248

43. Piwowarczyk A, Ottl P, Lauer HC, Kuretzky T (2005) A clinical report and overview of scientific studies and clinical procedures conducted on the 3M ESPE Lava All-Ceramic System. J Prosthodont 14:39-45. https://doi.org/10.1111/j.1532-849X.2005. 00003.x

44. Ural C, Burgaz Y, Sarac D (2010) In vitro evaluation of marginal adaptation in five ceramic restoration fabricating techniques. Quintessence Int 41:585-590

45. Bindl A, Mormann WH (2007) Fit of all-ceramic posterior fixed partial denture frameworks in vitro. Int J Periodontics Restorative Dent 27:567-575

46. Asavapanumas C, Leevailoj C (2013) The influence of finish line curvature on the marginal gap width of ceramic copings. J Prosthet Dent 109:227-233. https://doi.org/10.1016/S0022-3913(13) 60049-9

Publisher's note Springer Nature remains neutral with regard to jurisdictional claims in published maps and institutional affiliations. 


\section{Authors and Affiliations}

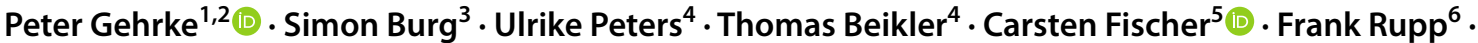 Ernst Schweizer ${ }^{6} \cdot$ Paul Weigl $^{1} \cdot$ Robert Sader $^{7} \cdot$ Ralf Smeets $^{3,8} \cdot$ Sogand Schäfer $^{3}$}

Simon Burg

s.burg@uke.de

Ulrike Peters

u.peters@uke.de

Thomas Beikler

t.beikler@uke.de

Carsten Fischer

fischer@sirius-ceramics.com

Frank Rupp

frank.rupp@med.uni-tuebingen.de

Ernst Schweizer

ernst.schweizer@med.uni-tuebingen.de

Paul Weigl

weigl@em.uni-frankfurt.de

Robert Sader

r.sader@em.uni-frankfurt.de

Ralf Smeets

r.smeets@uke.de

Sogand Schäfer

sog.schaefer@uke.de
1 Department of Postgraduate Education, Center for Dentistry and Oral Medicine (Carolinum), University Hospital, Goethe University Frankfurt, 60528 Frankfurt am Main, Germany

2 Private Practice for Oral Surgery and Implant Dentistry, Bismarckstraße 27, 67059 Ludwigshafen, Germany

3 Department of Oral and Maxillofacial Surgery, University Medical Center Hamburg-Eppendorf, 20251Hamburg, Germany

4 Department of Periodontics, Preventive and Restorative Dentistry, University Medical Center Hamburg-Eppendorf, 20251 Hamburg, Germany

5 Dental Laboratory, Sirius Ceramics, 60528 Frankfurt am Main, Germany

6 Section Medical Materials Science and Technology, University Hospital Tuebingen, 72076 Tuebingen, Germany

7 Department for Oral, Cranio-Maxillofacial and Facial Plastic Surgery, Medical Center, University Hospital, Goethe University Frankfurt, 60528 Frankfurt am Main, Germany

8 Department of Oral and Maxillofacial Surgery, Division of Regenerative Orofacial Medicine, University Hospital Hamburg-Eppendorf, 20251 Hamburg, Germany 